\title{
Explorative healthy aging approaches fostering social innovation: thematizing life course narratives of older women participating in a documentary film
}

\author{
Susie Riva-Mossman, ${ }^{1}$ Henk Verloo ${ }^{2}$ \\ ${ }^{1}$ University of Applied Nursing Sciences, Lausanne; ${ }^{2}$ University of Applied Nursing Sciences of Western Switzerland, Sion, Switzerland
}

\begin{abstract}
The transformative process of investigating life stories and their impact on healthy aging has only recently been explored. The relationship between hope and individual healthy aging strategies is still an under-researched area. This study contributes to filling the knowledgeability gap. The authors examine senior stories of hope and the experience of self-determination and well-being. The study documents the social learning processes of older people as they narratively search for solutions and imagine a hopeful future of healthy aging. A group of four older women participated in a semi-structured filmed interview, questioned by an academic expert. Healthy aging emerged as an important concern among all participants, confirming the need to actively learn how to age well. This exploratory research brought forth thematic clusters, orienting shared value solutions to demographic change. Qualitative research methods reinforce lifelong, collaborative learning processes that not only produce scientific literature, but also put in place relational networks that can grow and endure over time, generating social innovation. The film documented the role of hope and resilience in healthy aging.
\end{abstract}

Correspondence: Susie Riva-Mossman, University of Applied Nursing Sciences, La Source 30, Avenue Vinet, 1004 Lausanne, Switzerland.

Tel: +41.27.306.65.08.

E-mail: su.riva@bluewin.ch

Acknowledgements: we thank our partners Luc Bergeron, Nathalie Nyffeler, Elena Muggelini, Delphine Roulet Schwab and Nataly Viens Python for their participation in this research project. We also thank the University of Applied Sciences Western Switzerland, ECAL, Lausanne, Switzerland, the University of Applied Sciences Western Switzerland, School of Business and Engineering, Yverdon, Switzerland, and the University of Applied Sciences Western Switzerland, School of Engineering and Architecture, Fribourg, Switzerland for their contribution.

Conflict of interest: the authors declare no potential conflict of interest.

Funding: this research project was funded in part by Gebert Rüf Stiftung and the University of Applied Sciences Western Switzerland School of Nursing La Source, Lausanne, Switzerland. The sponsors played no role in the design and conduct of the research project, nor in the preparation, review, or approval of the manuscript.

Contributions: SR-M, data acquisition; HV and SR-M, study concept, data analysis and interpretation, manuscript drafting and follow-up.

Key words: Appreciative inquiry; Community-based participatory research; Epigenetics; Grounded theory; Healthy aging.

Received for publication: 25 July 2016.

Revision received: 12 October 2016.

Accepted for publication: 13 October 2016.

This work is licensed under a Creative Commons Attribution NonCommercial 4.0 License (CC BY-NC 4.0).

(C) Copyright S. Riva-Mossman and H. Verloo, 2017

Licensee PAGEPress, Italy

Qualitative Research in Medicine \& Healthcare 2017; 1:14-22

doi:10.4081/qrmh.2017.6199

\section{Introduction}

This paper presents the results of qualitative research conducted among female seniors, exploring the relationship between the life course, hope and healthy aging in French-speaking Switzerland. In this context, healthy aging refers not only to biological and medical aspects of aging, but includes phenomenological appreciations, functional definitions emphasizing autonomy, social participation and well-being, and aging as a process rather than a state. ${ }^{1}$ It focuses on the role of hope in learning lives, and its place in healthy aging as a critical factor in maintaining and improving quality of life among seniors. Aforementioned concerns are increasingly relevant in the light of current health and social care policies that aim to foster healthy aging using an ecological approach. ${ }^{2}$

We analyzed hopeful aging life courses thematically, using senior life stories to orient citizen-centered inquiry by including in-depth narratives that articulate a variety of appreciative reflections, insights, and behavioral strategies. ${ }^{3}$ As we understand it, healthy aging is contingent upon sufficient environmental, financial, and social support being provided, as well as seniors' physical ability to maintain a high quality of life, level of activity, and sense of independence. ${ }^{1}$ The availability of support networks assisting seniors vary in conjunction with local contexts. ${ }^{4}$ However, when local social support systems can be maintained, overall healthy aging is not just witnessed and modeled, but engendered within communities. This paradigm change transforms the image of seniors and their potential quality of life at the age of retirement. Positive life course perceptions in relation to aging may enhance wellbeing and autonomy among seniors. ${ }^{5}$ How we talk about 
aging as well as how we collectively perform aging have an effect on how we experience aging and retirement as an opportunity to do what we love to do.

Healthy aging has been conceptualized from a number of different perspectives. The biomedical perspective highlights the elimination of chronic illness risk factors and the promotion of optimal responses to illness. ${ }^{1}$ A more holistic perspective encompasses epigenetics. We adopted the definition of epigenetics evoked by Egger and colleagues as: the heritable changes in gene expression (active versus inactive genes) that does not involve changes to the underlying DNA sequence which in turn affects how cells read the genes. ${ }^{6}$ Epigenetic change is a regular and natural occurrence but can also be influenced by several factors including age, the environment/lifestyle, and disease state. Epigenetic modifications can manifest as commonly as the manner in which cells terminally differentiate to end up as skin cells, liver cells, brain cells, etc. Or, epigenetic change can have more damaging effects that can result in diseases like cancer.

This perspective underscores the pertinence of various psychosocial dimensions, including individual dispositional factors, social support networks, and attention to structural and environmental inequalities (Figure 1). ${ }^{7,8}$ Whose definition of healthy aging should be considered? Bartlett and Peel propose the following definition: ...to reflect the realities of aging, the most appropriate people to define what healthy aging means are seniors themselves. ${ }^{7}$ Notably, senior health narratives can vary with age, sociocultural context and gender, and are influenced by a person's perceived chances of healthy aging as well as the roles and representations associated with aging. ${ }^{9}$ Barlett and Peel mention that a number of consistent

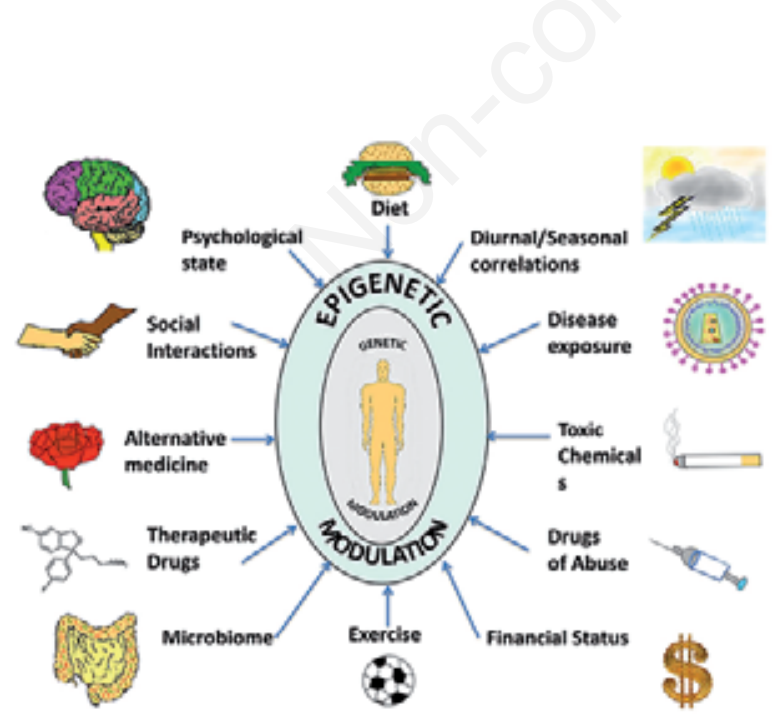

Figure 1. A compilation of epigenetic influences on humans. Reproduced from Open Access paper: Kanherkar RR, Bhatia-Dey $\mathrm{N}$ and Csoka AB (2014). Epigenetics across the human lifespan. Front. Cell. Dev. Biol. 2:49. doi:10.3389/fcell.2014. 00049. Available from: http://journal.frontiersin.org/article/ 10.3389/fcell.2014.00049/full themes have emerged from recent studies in healthy aging: For the individual, healthy aging means having a sense of well-being, the capacity for independent activity, meaningful involvement, supportive environments and positive attitudes. Being healthy is seen as having the resources for an everyday life that is satisfying to self and others. ${ }^{7}$ The subjective dimension is of particular importance as seniors may consider themselves as healthy within their own meaning systems irrespective of chronic illness. ${ }^{10}$ Moreover, while physiological, functional, and psychosocial issues have been strongly featured in scientific literature, the role of the life course in healthy aging has only recently been explored. ${ }^{4}$ Researchers have begun to draw out some of the implications of life course theory, life stories and healthy aging among seniors, and their impact on health-related outcomes. ${ }^{11}$ Research that explores the notion of hope is also enabling seniors to experience health and social well-being. ${ }^{12}$

Summing up, healthy aging is a highly fluid and complex issue, which requires further studies examining the relationship between hope, and individual aging strategies adopted by seniors. More research is needed in order to develop theoretical and empirical understanding of this under-researched area. The challenge of demographic change in Europe makes healthy aging a research priority in democracies where birth rates are plummeting and immigration is politically controversial. ${ }^{13}$

\section{Context of the study}

Older adults connected through embodied narratives of resilience, illustrating their know-how while facing the challenges of healthy aging. The Senior Living Lab (SLL) project focused on these senior voices..$^{14}$ Living Lab methods were used to explore nutrition and mobility with four university faculties and local stakeholders in the Frenchspeaking part of Switzerland. ${ }^{15}$ The SLL is in-formed by co-designed dialogical space, where participants meet and share strategies, finding ways to go forward while facing life events in relation to aging. Our action research project gives recognition to women's capacities to shape hopeful life scenarios. ${ }^{16}$ Our learning community gathered participants in a joint action, coordinating citizen-centered services and cultural activities to enhance the meaningmaking process throughout the life course. ${ }^{17}$

The SLL provides a platform, fostering the cross-pollination of projects with older adults referred to as seniors. It is a form of living laboratory promoting user-centered innovation. ${ }^{15}$ Lifelong learning entails relational and dialogical connection capable of spawning hopeful narratives for women. The SLL has offered a collaborative and interdisciplinary platform where aging men and women can envision growing old within a hopeful societal narrative, sharing their vision within their communities. This learning organization platform espouses an interdisciplinary approach to a societal challenge: demographic transition. The SLL goal is to give value to user-centered innovation 
processes. The digital community of the SLL reflects the activities that are being carried out in the field with the interested community partners, stakeholders, and researchers. ${ }^{18}$ The virtual platform enhances the relational potential of the living lab, communicating news, events, and publications. ${ }^{14}$ The SLL sought to make hopeful healthy aging a collaborative endeavor and a community performance. Our innovative methods contributed to creating shared value orienting joint actions. ${ }^{19}$

\section{Achieving social innovation through narrative transformation}

This quest for meaningful lives is a central mission in the ongoing process, engendering social innovation by articulating hopeful narratives that can foster embodied wellness. Transcending stories is part of the narrative process that challenges to transform the complexities in a storyline, pointing to larger human and cosmic stories. ${ }^{20}$ Randall and McKim declare: Given this progression from affirmation to transformation, reading brings us to The End, then, to a new mode of being in the world. ${ }^{21}$ New worlds are created through our relationships with communities. Writing our lives is something we do in conjunction with others. This underpins McNamee and Gergen's statement: We shape the world in which we live, thereby creating our own 'reality' within a context of a community of others. The boundaries of our narratives are constructed through political, economic, social and cultural constraints and potentials, with our choice of narratives not limitless, but existing within prescribed contexts. ${ }^{22}$

The voices of older women set the course for social innovation by describing their perception of life escaping a hopeful future. Their insights are guiding the interdisciplinary research team on the trail of innovation. The narratives shared in the documentary are a central part of the needs assessment phase, documenting perceptions of healthy aging. At first, the SLL co-created methods that led to joint action in the social designing of environments and services facilitating senior autonomy.

\section{Framework of the exploratory research}

This exploratory study uses qualitative research methods to better understand epigenetic factors in healthy aging. Recent research asserts that epigenetic changes occur with age. ${ }^{23}$ Advances in the field of epigenetics have increased our understanding of the association between disease states and methylation patterns. Epigenetic changes occur with age but also the environment as well as perception can contribute to the diversity in individual epigenetic changes. Finally, altered epigenetic patterns could play a role in delaying age-associated diseases and improve life expectancy. ${ }^{24}$

The objective of our study was to explore senior stories of hope, documenting social learning processes of older people as they search for solutions and imagine a hopeful, healthy aging future while narrating the subjective experience of self-determination, independence and wellbeing. Informative themes emerged from the accounts and experiences of individuals. We addressed two specific research questions: i) how do female seniors articulate hope in the concept of healthy aging? ii) How do resilience strategies support their efforts towards healthy aging? Resilience is understood to be the ability to overcome challenges that were faced by the women at the retirement age. Resilience strategies refers to the manner in which the women found creative solutions, overcoming problems that presented themselves while growing older. ${ }^{25}$

\section{Materials and Methods}

Grounded theory underpinned the investigation process. ${ }^{26}$ Image was used to frame the interviews. Filmed conversations captured the narratives in a documentary later shown within a community setting. Appreciative inquiry oriented the questioning process. Community Based Participatory Research (CBPR) methods, involving seniors in tandem with university researchers, provided a foundation for citizen-centered inquiry. ${ }^{27}$ Finally, social constructionist approaches offered a theoretical backdrop where dialogical space was co-created engendering a field of research and a space for community performance. ${ }^{28}$ Filmed interviews were employed, creating a film documentary. The film shared stories of hope with the local public. The main intent was to show the women's resilience strategies. Filming was favored over transcribing the interviews in an effort to reach the greater public.

\section{Research procedure, data collection process, and participative analysis}

Four senior women from the SLL including a professor and member of Via Mulieris, a regional association dedicated to gathering women's stories, were invited to participate in this exploratory study. All participants gave a written informed consent allowing their filmed interview to be used and were free to withdraw at any time. An interview framework was developed from knowledge of the literature on the life course, health and aging, life stories, resilience and hope. But most of all, the interviews were inspired by the informal conversations that were shared during the ethnographic research sessions in the field.

This study employs filmed narratives to gather data about older adults in Valais. The women shared their experience of growing old, explaining how they continue to participate within their social networks. The place of hope in learning lives orients the questioning process, with stories that offer images of potential and hope. ${ }^{28}$ The narrative approach sought to include senior perceptions in tandem with professional researchers, co-constructing the investigative processes carried out in the field.

The initial SLL framework used needs assessment, 
leading to conversations that ultimately explored resilient life stories. To accomplish this exploratory research, an interdisciplinary approach was chosen favoring an epigenetic vision of aging. A semi-structured questionnaire was created to provide a canvas for the interviews and was organized around five key topic areas to elicit conversations during the filming of each participant: the meaning-making process, lifelong learning and autonomy, social and community participation, health and well-being, and technologies and other social support for aging-in-place. The in-depth interviews explored seniors' perceptions through collaborative conversations. A SLL researcher and senior film producer edited the film content. Together they spliced and mixed the film content, co-creating the film documentary and reinforcing the communication of the guiding themes.

The senior participants viewed the documentary with the SLL researcher during a screening organized to ascertain the major themes expressed in the filmed interviews. The narratives in-formed the thematic clusters that were identified. In this way, the volunteer seniors were participants alongside the researcher, highlighting the CBPR approach in this project. Senior knowledgeability informed the investigation phases alongside the university team. The interviews give value to personal narratives of hope when facing the promise of increased longevity. The stories contribute to the Swiss, French-speaking region's efforts to imagine a bright future for older adults. The Via Mulieris Association and the Cantonal Committee on Ethics in Research Involving Humans in Valais both gave their approval for the study.

\section{Participative analysis}

Following the data collection process, interviewees and participants at the Avant-Première collaborated in the analysis of the film documentary. This meaning-making process combined various World Café techniques, ${ }^{29} \mathrm{al}-$ lowing participants to feel free to express their ideas in a collaborative co-construction process. The Avant-Première event used the film to create reflexive community space, enhancing the knowledgeability of the participants. Volunteers at the event filled out a questionnaire that was later analyzed. The thematic content provided even more depth to the film's narratives. Coherent insights took form through the conversations and questionnaires, where shared emic perceptions brought forth theories pertaining to healthy aging.

\section{Results}

Healthy aging emerged as an important concern among all film documentary participants; women between 61 and 75 years old. All participants had a higher education level and socio-economic status. Their notions of healthy aging were diverse and involved functional, psy- chological, social and physical dimensions. In particular and demonstrated by Baltes and colleagues, participants saw their personal control, or the ability to make their own choices, as integral to a healthy lifestyle.$^{30}$ Healthy aging was seen as something that older people could learn, do or work towards, highlighting a sense of agency in old age. Women evoked emergent themes in relation to hope's role in supporting or constraining the process of healthy aging. They found their own relevant form of resilience while facing challenges at the age of retirement. Their stories demonstrate how they were able to perform learning lives capable of adapting and adjusting to life-course changes. The group analysis of the film content at the screening, followed by the première event, created an ever-growing space of reflexivity focused on hopeful healthy aging. In reference to McIntyre's description of narratives that are much like recipes that have to be put into storied sequences if they are to make sense, the women contextualized their personal stories of hope, explaining the ingredients incorporated into the batter of their retirement cake. ${ }^{31,32}$

The Avant-Première provided a community event bringing together the various stakeholders. The city's social services, the canton's health promotion platform for $60+$, the president of the Via Mulieris Association, as well as the editor of a regional magazine dedicated to seniors, participated in a round table discussion in relation to the film, adding to the regional meaning-making process.

Because of confidentiality issues, we have chosen not to develop in depth the personal stories of the women participants. We have favored using their quotes from the film that share glimpses into their life stories. To provide a backdrop for their narratives, we have included the following brief vignettes of each senior participant: one woman was a journalist that became a sculptor; she invites us to her workshop in the film.

Another participant was in banking, she explains the importance of financial planning; she created an association to integrate women's voices into local historical accounts motivated by the bicentennial year celebration. Still another participant was the head of a nursing home and used her many care giving skills to take care of her mother upon retirement.

Finally, another woman's testimony explains how her work in human resources motivated her to train as a mediator, giving value to the meaning-making process and providing new skills to use as a volunteer for battered women. The fifth contributor, a sociology professor specialized in aging, offered a scientific narrative based on her research.

\section{Emerging themes}

The themes that emerged from the narrative content enriched the reflexive space by incorporating individual insights and connecting them to emerging patterns that ran throughout the five narratives documented in the film. The 
group analytical work allowed the participants to identify patterns of coherence, transcribing their understanding of the narrative's meaning into an even more explicit written form on note cards. Participants evoked several substantial contributing components, creating Shared Value in relation to healthy aging. Shared Value refers to the creation of social and economic value and advancing social progress. ${ }^{19}$ They mentioned transmission and the sharing of knowledge and life experiences, respect for personal rights and the freedom to choose, and reciprocity understood as a healthy balance between giving and receiving. The cycle of life that allows us to give back what we have received. The aforementioned themes were expressed as core components of hopeful healthy aging. Imagining a hopeful future and sharing messages of hope with the greater community, by giving testimony to the opportunities retirement has to offer, was the central mission of the film process. Being able to give voice to senior perceptions is capital, what is essential is the ability to communicate. ${ }^{33}$ Moreover, diverse meaning-making processes were beneficial resilience strategies, for example: creating art, developing associations, movies, and serenity-seeking pathways cultivating well-being. A participant highlighted, I love challenges! Another woman explained while sculpting in her workshop, The need for beauty is important to me. I am sculpting a body. It is a form of search for the sacred, beauty, and perfection. Participants also evoked gratitude and the importance of being thankful for the professional and family relationships that make life meaningful. One spoke of her daughter who has special needs stemming from a medical error occurring at her birth saying, My experience with my daughter was a key element in my life. Her admiration for her daughter's resiliency was a driving force in her own personal development.

For participants, lifelong learning included the ability to find the necessary resources needed to cope with changing life circumstances, resiliently moving forward. By developing self-efficacy, they were able to recover from hardship, continuously adapting to new situations throughout the life course. One participant spoke of growing older but better, describing, the apprenticeship of growing older. While another woman accentuated the importance of maintaining relational links. Their testimonies correspond with Hammond's research that documents the link between lifelong learning and emotional resilience. ${ }^{34}$

The economic, social, and relational contributions after retirement were perceived as critical success points in healthy aging, inspiring community agency focused on imaging new ways of living together in a society with increasing percentages of people over 60 years old, an evolving society where today's women can, dare to say their mind. The sociology professor evoked the possibility of imaging new social forms when facing vulnerability underscoring, A potential for social innovation. She also explained, Older people continue to tell the family story, transmitting it to grandchildren.
A core theme was financial planning, using state and personal retirement options to organize and plan for the future, funding a new phase of life. One woman stated, Loans are difficult to obtain after retirement. Participants recognized the important social and financial resources of retirees: gifts, babysitting, community contributions through volunteer work and the growing silver economy. However one woman commented, At 60 you get a label. She went on to explain, We must think of our retirement funds because we have interruptions in our career with children. She also highlighted the adverse effects of divorce on retirement savings because of salary inequalities and the time women often give to their family, reducing their own financial savings.

Participants acclaimed the effectiveness of the medical, social and sanitary improvements in Western society that have engendered current standards of quality of life where elders can live well longer. Pointing to architectural changes favoring aging at home, one woman proclaimed, The creation of home care is a revolution. Highlighting the importance of social security she said, We are retired with a revenue. The challenge of life escaping was seen as a noble human endeavor. The gift of thirty added years to the lifespan was understood as an opportunity. Resilience strategies allowed the women to be happy, transcending their misfortunes. Growing older was correlated with a changing relationship to time, slowing down and appreciating the time one has, the seasons, and the natural rhythms that are modified with age. One participant said, I thought I would have more time. While another commented how notions of time are transformed at the retirement age. Although participants spoke of mourning past deceptions, they explained how grieving paved the way to satisfaction with everyday life: free to live fully in the present. I never would have imagined so much harmony in this stage of life was one woman's observation. Most participants found strength and support in community; coming together with renewed vitality. They spoke of giving more time to contemplation and getting rid of all that is superfluous. One woman declared, I didn't want to have an abrupt change at my retirement, explaining why she began classes to become a sophrologist. She told how difficult it can be to suddenly leave the work environment and therefore important to question, What is my self worth and what is my role on earth? Participants expressed how an improved societal vision of care buttressed the current possibilities for healthy aging with the, capacity to make decisions. The evolution toward a more interdisciplinary approach to care was also perceived as engendering systemic improvements. Envisioning health and aging in more ecological and environmental terms, in keeping with an epigenetic vision of healthy aging, was acclaimed as, a more positive vision. Still, one woman warned against, the denial of growing older and death. All participants were in favor of innovative technologies and consider these developments as beneficial, bringing advances in communication, smart 
living, commercial services, as well as holistic care improvements in order to, adapt, continually adapt. However, one participant asked, What is the impact? when referring to new technologies and social innovation.

During the Avant-Première event, 18 participants filled out a questionnaire. Most participants were female (16/18), between 45 and 88 years of age. All but two considered hope an important factor in healthy aging. The participant's perceptions of the film content confirmed the importance of actively learning how to age well. Healthy aging was seen as a responsibility that communities and individuals must jointly cultivate. Retirement was perceived as a new phase in life that requires preparation. Gaining knowledge about healthy lifestyle choices as well as financial planning were both mentioned, as was the necessity to personally engage in the continuous meaningmaking process through creative endeavors, asking about the meaning of life.

The audience participants inquired about our choice of interviewees in our initial film and exploratory research. In the group discussion as well as in the questionnaire, our methodological approach was seen as an example that could be extended to other categories of seniors. Participants thought that including other groups in the inquiry process would enrich the development of theme clusters. Suggestions were made to include men, frail and vulnerable seniors, as well as less advantaged social and economic groups of elders. The event and ques- tionnaire served to orient our future research projects, confirming the relevance of our methods; incorporating documentary and social change processes to better understand the place of hope in researching learning lives.

\section{Discussion}

A hopeful healthy aging model was configured using film documentary. The film project provided a reflexive space during the interview process, during the senior group analytical process, culminating at the Avant-Première event where all the stakeholders participated in the snowballing conversation. Citizens and stakeholders joined in a generative process that concluded with a collaborative performance envisioning a bright future.

New forms of relational welfare can be co-constructed in collaborative practices that give rise to social transformation processes. Using testimonials in filmmaking processes to elicit insights and conversations in relation to hopeful healthy aging is in itself a form of methodological innovation. This exploratory research brought forth thematic clusters, orienting shared value solutions to demographic change. The social innovation outcomes are difficult to estimate, however, the reflexive dialogical process that the SLL initiated has given rise to increased knowledgeability within the network of stakeholders. The themes that emerged were configured into clusters of

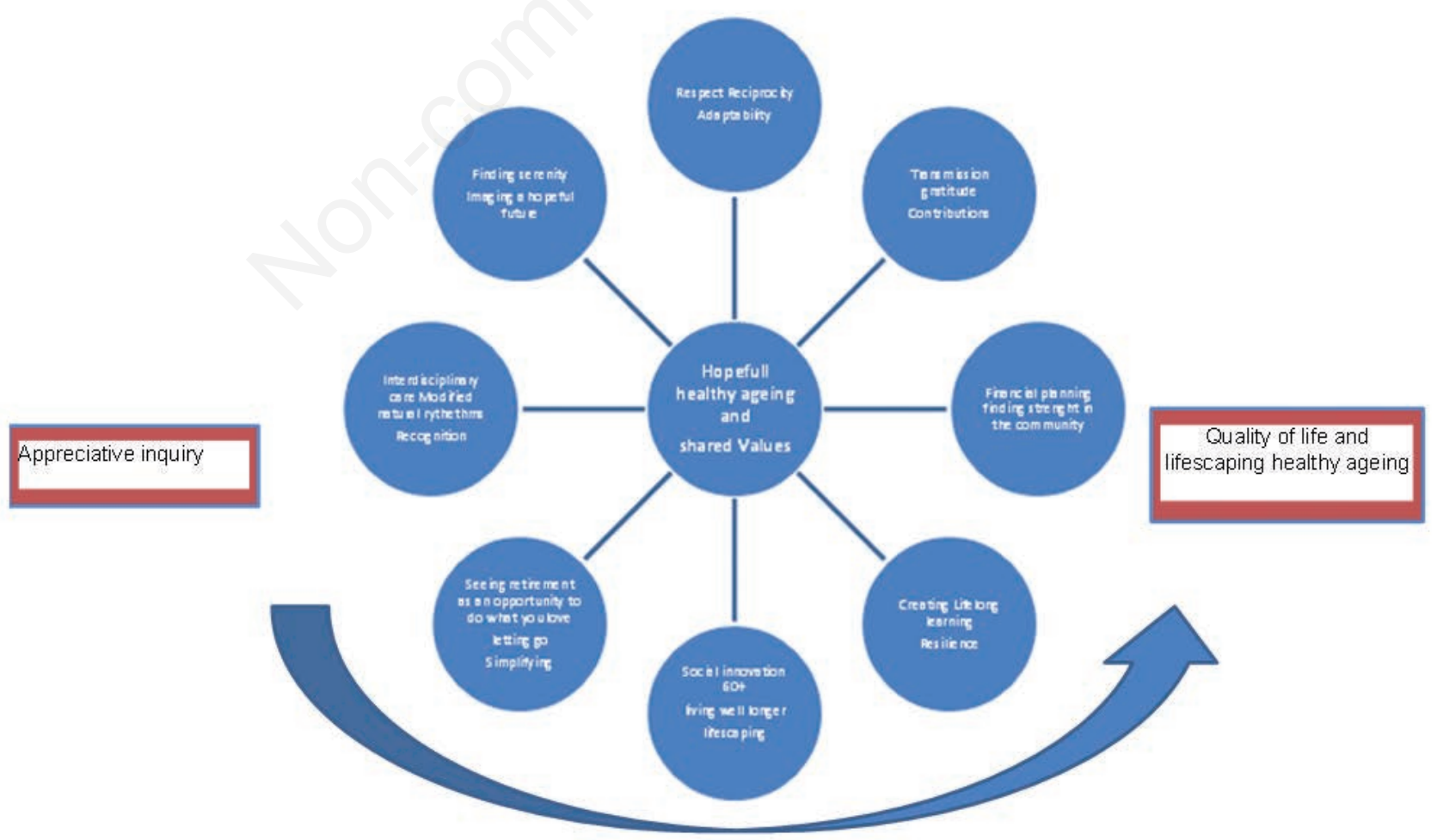

Figure 2. The hopeful health-aging model. 
meaning that can serve as a basis for a hopeful health model (Figure 2).

\section{New paradigms: epigenetics and the health model}

Most people received a gift of thirty years added on to their lifespan. This gift from our ancestors can be appreciated and used to the fullest. The new epigenetic paradigm and research area stresses how environment and perceptions can influence the expression of DNA. ${ }^{35}$ This understanding underscores the importance of health prevention that begins at conception and must be sustained throughout the life course. ${ }^{36}$ Healthy life choices are understood to influence epigenetic expressions. Non-genetic regulation of aging is gaining scientific attention in an attempt to better understand the potential reversibility of epigenetic changes and the plasticity that may be harnessed when approaching aging and age-related diseases from a new angle: The main appeal of understanding the environmental non-genetic regulation of aging is to open new avenues for actionable interventions that could benefit the diseases of age. ${ }^{37}$ Lifelong learning offers older people the opportunity to adjust their lifestyles by integrating new research on healthy living. Participants vocalized the need to shift our focus from a disease model to a health model (Figure 2). ${ }^{38}$

\section{Life long learning}

Bandura's work on self-efficacy and the important influence of positive models underscores the potential within a learning film capable of eliciting positive behavior in viewers: Seeing people similar to oneself succeed by perseverant effort raises observers'beliefs in their own abilities. ${ }^{39}$ Collective efficacy is necessary when facing societal challenges like demographic change. There is an important transition from traditional research methods that mirror and describe toward methods that foster social innovation. ${ }^{40}$

Research design has the potential of engendering social transformation. ${ }^{28}$ Our choice of data collection methods mediates individual experience with communal responsibility. ${ }^{41}$ As more and more citizens become aware of the demographic transformation and the challenge caring for a growing aging population presents, interdisciplinary actions will need to be coordinated to meet future needs. This should not be limited to social and healthcare professionals, but municipalities and communities can begin imaging ways to go on together by anticipating reinforced retirement programs, educational trajectories, healthcare coordination, and life-course prevention policies. Sensitizing the greater public is an important aspect of the SLL's mission.

Research methods can reinforce lifelong, collaborative learning processes that not only produce scientific literature, but also put in place relational networks that grow and endure over time. The relational welfare engendered during the research phase gave rise to new forms of social relating, inspiring new social designs, orienting individual choices. ${ }^{42}$

\section{Narrating hopeful life-courses}

Our film celebrates hopeful, human narratives of aging. In a narrative or ritual manner, stories and rites symbolize a process of construction of this identity. They direct the roles to be played. ${ }^{43}$ Storying can therefore be seen as an activity that can influence how we grow old. As the senior women modeled resilient and hopeful lives on camera, they were speaking to a potential audience, hopefully activating community collaborations capable of informing future aging processes. Organizations and associations working on issues in relation to healthy aging should be encouraged to participate in community performance and social orchestration: And, overall, the story takes on meaning that previously we were unable to predict: indeed, meaning we may never fully fathom. In the end, the story points beyond itself..$^{44}$

Ethical elder care requires theoretical frameworks capable of integrating practice informed by patient and citizen needs. Interdisciplinary research teams including the nursing sciences can use methods that incorporate aesthetics to ascertain the sacred while facing aging, illness and death. The aesthetic approach incorporates the art and act of nursing. Ethical knowing, which constitutes the ethics of nursing, is generated by means of ethical inquiries that are focused on identification and analysis of the beliefs and values held by individuals and groups and the clarification of those beliefs and values. ${ }^{45}$ Watson's theoretical approach values a culture of care. ${ }^{46}$ She reserves an important place for aesthetics within her theoretical and philosophical framework, illustrating how artistic approaches to healing are capable of integrating the sacred. As one of our participants declared, The end of life evokes an immense respect highlighting the role of, creativity and innovation for well-being.

This scholarship endeavors to set a new life course using qualitative methods. ${ }^{47}$ Holistic methods can contribute to designing care for our elderly people and our planet while creating shared value. Our planet's elders are voicing the need for a Culture of Care and Planetary Wellness. Their wisdom can orient our care pathways when given dialogical and participatory space. This space, configured into our research models, allows integral research approaches to harvest social innovation in the narrative field of inquiry.

\section{Conclusions}

The SLL has brought together stakeholders that engage in interdisciplinary research with collaborative and transformative methods. Together participants crafted a platform responsive to demographic change. The SLL is 
driven by needs assessment methods allowing seniors in tandem with interdisciplinary researchers to perform social innovation, proposing new forms of data collection in an attempt to better understand healthy aging strategies. The multifaceted ways in which older people socially construct healthy aging have both practice and policy implications. At a practice level, this complexity needs to be more fully understood by the various professionals who provide daily care and support to older adults living at home, accentuating the importance of inter-professional collaboration. Heterogeneous data collection methods contribute by creating a more holistic and ecological vision of relational welfare. Healthy aging strategies dovetail with epigenetic patterns, in support of healthy aging. Equally, social and healthcare practitioners need to be aware of the important role that hope and resilience play in healthy aging. Finally, at a policy level, where macro socio-economic factors are considered, the social determinants of health should be recognized as having important implications that ultimately affect the health of older adults and the viability of their communities.

\section{References}

1. Hansen-Kyle L. A concept analysis of healthy ageing. Nurs Forum 2005;40:45-57.

2. Sixsmith A, Sixsmith J. Ageing in place in the United Kingdom. Ageing Int 2008;32:219-35.

3. Löfqvist C, Granborn M, Himmelsbach I, et al. Voices on relocation and ageing in place in very old age - a complex and ambivalent and matter. Gerontologist 2013;53:919-27.

4. Cutchin MP. The process of mediated ageing-in-place: a theortically and empirically based model. Soc Sci Med 2003; 57:1077-90.

5. Rosel N. Aging in place: knowing where you are. Int J Aging Hum Dev 2003;57:77-90.

6. Egger G, Liang G, Aparicio A, Jones PA. Epigenetics in human disease and prospects for epigenetic therapy. Nature 2004;429:457-63.

7. Bartlett H, Peel N. Healthy ageing in the community. In: Andrews GPD, ed. Healthy ageing in the community. London: Routledge; 2005. pp 98-109.

8. Kanherkar RR, Bhatia-Dey N, Csoka AB. Epigenetics across the human lifespan. Front Cell Dev Biol 2014;2:49.

9. Kleinman A. The illness narratives: suffering, healing and the human condition. New York: Basic Books, Inc.; 1990.

10. Bryant L, Corbett K, Kutner J. In their own words: a model of healthy ageing. Soc Sci Med 2000;53:927-41.

11. Oswald F, Wahl HW, Schilling O, et al. Relationship between housing and healthy aging in very old age. Gerontologist 2007;47:96-107.

12. Wiles JL. Home as a new site of health care consumption. London: Routledge; 2005.

13. WHO. Guide mondial des villes amies des aines. 2007 Available from: http:/www.who.int/ageing/publications/ Guide_mondial_des_villes_amies_des_aines.pdf

14. Lab SL. Senior Living Lab Lausanne: HES-SO; 2015. Available from: www.seniorlivinglab.ch
15. Riva-Mossman S, Kampel T, Cohen C, Verloo H. The Senior Living Lab: an example of nursing leadership. Clin Interv Aging 2016;11:255-63.

16. Via Mulieris. Via Mulieris Sion 2016. Available from: http://www.via-mulieris.ch/

17. Ståhlbröst A, Holst M. The Living Lab methodology handbook. Luleå: Luleå University; 2012.

18. Wenger E, White N, Smith JD. Digital habitats: stewarding technology for communities. Portland, OR: CPsquare Publications; 2009.

19. Porter ME, Kramer MR. Creating shared value. Harvard Bus Rev 2011;89:1-2.

20. Randall WL. Transcending our stories: a narrative perspective on spirituality in later life. Crit Soc Work 2009;10:31-46.

21. Randall WL, McKim E. Reading our lives: the poetics of growing old. New York: Oxford Scholarship online; 2008.

22. McNamee S, Gergen K. Therapy as social construction. New York: Sage; 1992.

23. Brooks-Wilson AR. Genetics of healthy aging and longevity. Hum Genet 2013;132:1323-38.

24. Gravina S, Vijg J. Epigenetic factors in aging and longevity. Pflugers Arch 2010;459:247-58.

25. Laprie J-C ed. From dependability to resilience. $38^{\text {th }}$ IEEE/IFIP Int Conf On Dependable Systems and Networks: Citeseer; 2008.

26. Charmaz K. Constructing grounded theory: a practical guide through qualitative analysis. London: Sage Publications; 2006.

27. Doyle M, Timonen V. Lessons from a community-based participatory research project: older people's and researchers' reflections. Res Aging 2009;32:244-63.

28. McNamee S, Hosking DM. Research and social change: a relational constructionist approach. New York: Routledge; 2012.

29. Brown J, Isaacs D. The World Café: shaping our futures through conversations that matter. San Francisco: Berrett Koehler Publishers; 2005.

30. Baltes PB, Baltes MM. Psychological perspectives on successful aging: the model of selective optimization with compensation. In: Baltes PB, Baltes MM, eds. Successful aging: perspectives from the behavioral sciences. New York: Cambridge University Press; 1990. pp 1-34.

31. MacIntyre A. After virtue: A\&C Black; 2013.

32. Gergen KJ. Narrative, moral identity, and historical consciousness. In: Straub J ed. Narrative, identity and historical consciousness. New York: Berghahn; 2005. pp 99-119.

33. Riva Mossman SK. Creating dialogical space in generative research using professional's narratives. Nova Perspect Sistêmica 2015;52:33-51.

34. Hammond C. Impacts of lifelong learning upon emotional resilience, psychological and mental health: fieldwork evidence. Oxford Rev Ed 2004;30:551-68.

35. Ashapkin VV, Kutueva LI, Vanyushin BF. Aging epigenetics: accumulation of errors or realization of a specific program? Biochem Moscow 2015;80:1406-17.

36. Beerman I, Rossi DJ. Epigenetic control of stem cell potential during homeostasis, aging, and disease. Cell Stem Cell 2015;16:613-25.

37. Brunet A, Berger SL. Epigenetics of aging and aging-related disease. J Gerontol A Biol Sci Med Sci 2014;69:S17-20.

38. Karlic H, Baurek P. Epigenetics and the power of art. Clin Epigenet 2011;2:279.

39. Bandura A. An agentic perspective on positive psychology. 
In: Lopez SJ ed. Positive psychology: expecting the best in people. Vol 1. New York: Praeger; 2008. pp 167-96.

40. Gergen KJ. From mirroring to world $\square$ making: research as future forming. J Theory Soc Behav 2014.

41. McNamee S, Gergen KJ. Relational responsibility: resources for sustainable dialogue. Thousand Oaks, CA: Sage publications; 1998.

42. Cottam H. Relational welfare. Soundings 2011;48:134-44.

43. Brandt P-Y, Fournier C-A, Mohr S. Religion and spirituality in psychiatry. Cambridge: Cambridge University Press; 2009. pp 158-72.

44. Randall WL, McKim AE. Reading our lives the poetics of growing old. New York: Oxford University Press; 2008.

45. Fawcett J, Watson J, Neumann B, et al. On nursing theories and evidence. Philosophical and theoretical perspectives for advanced nursing practice. Burlington, MA: Jones and Bartlett Learning; 2013.

46. Watson J. Theory of human caring. Available from: http:// www.watsoncaringscience.org/images/features/library/THE ORY\%20OF\%20HUMAN\%20CARING_Website.pdf

47. Reeder FM. What will count as evidence in the year 2050 ? In: Cody WK ed. Philosophical and theoretical perspectives for advanced nursing practice. Burlington, MA: Jones and Bartlett Learning; 2013. 